\title{
Students' Involvement in Social Networking and Attitudes towards Its Integration into Teaching
}

\author{
Ukeme Ekpedeme Umoh ${ }^{1} \&$ Etuk Nssien Etuk ${ }^{1}$ \\ ${ }^{1}$ Department of Curriculum Studies, Educational Management and Planning, Faculty of Education, University of \\ Uyo, Akwa Ibom State, Nigeria \\ Correspondence: Ukeme Ekpedeme Umoh, Department of Curriculum Studies, Educational Management and \\ Planning, Faculty of Education, University of Uyo, Akwa Ibom State, Nigeria. Tel: 234-806-747-9492. E-mail: \\ ukeme81@gmail.com
}

Received: February 29, 2016

Accepted: March 31, $2016 \quad$ Online Published: August 29, 2016

doi:10.5539/ies.v9n9p250

URL: http://dx.doi.org/10.5539/ies.v9n9p250

\begin{abstract}
The study examined 'Students' Involvement in Social Networking and attitudes towards its Integration into Teaching. The study was carried out in the University of Uyo, Akwa Ibom State, Nigeria. The population of the study consisted of 17,618 undergraduate students enrolled into full time degree programmes in the University of Uyo for 2014/2015 academic session. The design of the study was survey design with ex-post facto approach. Random sampling technique was used to select 1730 students from the 12 faculties in the University. The instrument used for the study was 'Students' Social Networking and Attitude Questionnaire which was validated by an expert in curriculum studies and an expert in measurement and evaluation in the University of Uyo. Cronbach's Alpha Statistical method was used to determine the reliability coefficient of .70 for the instrument. Two research questions and two null hypotheses tested at .05 level of significance guided the study. Mean and Standard Deviation were used to answer research questions; Independent t-test and Analysis of Variance were used to test the hypotheses. The results show that there is significant difference in involvement of university undergraduate students in Social Networking based on course of study, level (year) of study and age. Female undergraduate students' involvement in social networking is higher than that of their male counterparts; but male undergraduate students showed a higher positive attitude towards integration of social networking into teaching and learning.
\end{abstract}

Keywords: attitudes, involvement, social networking

\section{Introduction}

\subsection{Introduction to the Problem}

Educators have long searched for new technologies to aid their students in the process of learning and the earliest technologies used for teaching and learning was radio and television. Technological innovations have brought about the use of many other technologies such as networks websites. The University of Lowa offered the first application of educational television in 1946. According to Boyd and Ellison (2007) the first identifiable social networks website was launched in 1997, six to seven years before currently popular sites like Facebook, MySpace, and LinkedIn. Johnson, Levine, and Smith (2007) established that social networking has seen tremendous growth in recent years and was identified as an emerging technology for teaching and learning in 2005. Since then, the educational possibilities of social networking tools have been a recurring subject which seeks to identify current and emerging trends in technologies to support teaching and learning.

Undoubtedly, many of the teaching and learning activities that are currently being accomplished through learning management systems and other technologies can also be accomplished via some social networking systems like Facebook, WhatsApp, YouTube, Twitter, Skype, MySpace, and LinkedIn. These technologies are usually integrated directly into the curriculum as major curriculum content, or sometimes used as methods or approaches in teaching and learning curriculum contents. Although the emergence of social networking is a viable educational tool, the gap between students' perception and attitude towards its integration into teaching and learning continues to widen. Thus, as with any technology system designed for social interaction and repurposed for teaching and learning, a careful and informed integration process is necessary to provide a foundation for developing new teaching and learning activities (Ophus \& Abbitt, 2009). 
Johnson, Levine, and Smith (2007) also described the growth of mobile devices and the use of these devices with social networking systems as the emergence of a "personal web" through which students organize information and communication. The authors view social networking technologies as a mechanism to continue a conversation outside classroom walls and an easy way to update students on course logistics. Although the popularity of social networking sites among university students is undeniable, the potential for this technology to positively impact student learning remains uncertain. Despite the fact that social networking systems have been identified as having high potential to aid teaching and learning, the major questions to ask are: how much of the time students spend on phones and other ICT appliances are devoted to academic work? What are the university undergraduate students' attitudes toward integration of social networking into teaching and learning?

Studies reviewed have been concerned with the frequency of involvement in Social Networking, the perception and use of social network sites and the positive and negative impacts on University students; the perceptions on social networking and influence on academic performance, study hours and academic adjustment and social behaviour. None has addressed the University students' attitude towards the official integration of social networking into the official learning/learning process.

\subsection{Problem of the Study}

The popularity of social networking sites among university students is undeniable as students are heavily involved in social networking; despite the popularity of personal use of social networking sites, a low percentage of students and instructors use them for educational purpose. The majority of undergraduate students who spend most of their time on their ICT appliances such as phones, ipads and computers do so for fun and entertainment neglecting their academic work. National School Board Association (2007) reported from a study that students who are involved in social networking spend most of their time chatting, posting and sharing multimedia contents such as music, pictures and cartoons. Some students spend their time to seek relationships through social media; while some students are seen fiddling with their phones all the time even while on the roads. Hence social media could be a distraction from academic work even when social networking system provides an alternative approach to learning which is more learner-centred and enhances students' participation in teaching learning process.

Students' reading culture is paramount to their academic achievement, but there is an outcry on declining reading culture among students although social networking sites provide alternative means to accomplish and improve reading and learning as the case is in learning management systems and other technologies. While it would be possible to begin to integrate social networking systems into teaching and learning at the university level, it is important to determine the feasibility of such an effort and also to explore how students may respond to such an effort. However, whether or not such an effort is likely to succeed is among the first questions that need to be addressed. If such an effort has a reasonable chance of success at improving teaching and learning, it is also vital to examine students' disposition towards this technology as a tool which can enhance teaching and learning considering the manner in which this technology can be used to do so. Hence, this study sought to determine students' involvement in social networking and their attitudes towards its integration into teaching and learning in the University of Uyo, Nigeria.

\subsection{Related Literature}

With their increasing popularity, social networking sites have influenced various aspects of the society and have been integrated into the daily lives of web users (Zhang, 2013). The impact of social networking sites has also reached the educational sector. Educational institutions, individual teachers and learners have begun using social networking sites for the purpose of sharing knowledge and experiences. As an information source quickly gaining popularity, social networking sites have been touted as having great potential in promoting teaching and learning. To gain an understanding of the potential of social networking sites in promoting teaching and learning, it is necessary to know how users (students) learn (Zhang, 2013). The educational possibilities of social networking tools has been a recurring subject which seeks to identify current and emerging trends in technologies to support teaching and learning. However, Johnson, Levine, and Smith (2007) addressed social networking technologies as a mechanism to "continue a conversation outside of classroom walls or provide an easy way to update students' on course logistics". Though the popularity and extensive use of social networking systems is a relatively recent phenomenon in Nigeria, researchers have begun to investigate the educational applications of this technology.

Ophus and Abbitt (2009) established that central to the debate concerning the use of social networking systems in education is the knowledge that students are already heavily engaged in using social networking websites. As such, the question of whether social networking tools should be used in learning environments is better 
characterized as a question of repurposing an existing technology for teaching and learning. According to (Zhang, 2013) human factors and human-computer interaction researchers postulated that users' use and interaction with a system is mediated by their perceptions or mental models of the system. These perceptions impact users' understanding of the form, purpose and functions of a system.

Wolfe (2013) carried out a survey study on the topic "Student Attitudes towards Social Networks and learning modalities at Liberal Arts College on East Coast". The sample of the study is consisted 485 respondents, with roughly equivalent representation of each class year (level) from freshman through senior level. The ratio of females to males was approximately 3 to 2 (i.e 308: 177). The instrument used was a 12-items questionnaire designed to explore students' use of social networks and attitudes towards different learning modalities. The data generated was analyzed for trends relating social network usage to both demographic and educational preferences. The usage of social networks was correlated with class year, major, and gender. The results of this survey indicated that an overwhelming majority of students make use of social networks daily with nearly one third using multiple sites. There was minimal correlation between gender, class year (level), or major and the use of social networking.

Ahmad (2011) carried out a study on Social Networking Sites (SNSs) usage and Students Attitudes towards social behaviours (SSB) and Academic Adjustment (SAA) in Northern Nigerian universities. The variance in the extent of SNSs usage in relation to gender, age, faculty, ethnicity, social economic background and religion was also investigated. The moderating effect of attitude towards SNS usage was examined. Four hundred participants were sampled and they completed the questionnaire. In addition, 24 volunteered participants from six universities were interviewed and questionnaires employed. The data were qualitatively and quantitatively collected, sorted, analyzed and reported separately at significantly equal weight. The thematic qualitative analyses and the quantitative descriptive results suggested that the extent of social networking usage, the students' social behaviour and students' academic adjustment was high among the university students in Northern Nigeria. One way analysis of variance (ANOVA) also revealed that there were no significant differences in the extent of social networking sites usage by university students in terms of age, faculty, socio economic background and the level (year) of study. However, significant differences existed among ethnicity and religion. The independent sample-t tests revealed no gender differences in the extent of social networking usage. Similarly, the results of the study showed significantly positive inter-relationships among the social networking sites usage, students' social behaviours and students' academic adjustment. The findings also found attitude to be a strong prediction and moderator of relationship between the social networking sites and both students' social behaviour and students' academic adjustment.

Ahmad (2012) also conducted another study on 'Attitudinal disposition of Nigerian University students toward Social Networking Sites'. Four hundred university students were sampled from the Northern Region of Nigeria. The instrument used for the study was a questionnaire on Attitudinal Disposition of Nigerian university students towards social networking sites. The study investigated the difference in the disposition of university students towards social networking based on gender and faculties. ANOVA was used to analyze the data generated. The results of the findings showed that there was no significant difference in the disposition (attitude) of university students towards social networking sites based on gender and age. However, significant differences were found in terms of faculties.

Karpinksi and Duberstein (2009) sought to connect Facebook usage and academic achievement among college students in San Diego and found a significant difference between users and non-users of Facebook on both GPA and average hours spent studying. Facebook users $(n=148)$ had a GPA between 3.0 and 3.5 (out of 4.0) while non-users (n-71) typically had a GPA between 3.5 and 4.0. With regard to hours spent studying per week, Facebook users averaged between 1 and 5 hours per week, while non-users averaged between 11 and 15 hours per week. Though these differences do not imply causality (Karpinksi \& Duberstern, 2009), it provides a compelling reason to consider whether efforts to integrate social networking into college courses would be influenced by such differences or alleviate these issues by employing these systems for academic purposes.

Studies reviewed have been concerned with the frequency of involvement in Social Networking, the perception and use of social network sites and the positive and negative impacts on University students; the perceptions on social networking and influence on academic performance, study hours and academic adjustment and social behaviour. None has addressed the University students' attitude towards the official integration of social networking into the official learning/learning process. There is therefore a need to investigate this area and fill the gap. 


\subsection{Research Questions}

The following two research questions were raised.

1) What difference exists in the level of undergraduate students' involvement in social networking based on course of study, level of study, age and gender?

2) What difference exists in undergraduate students' attitude towards integration of social networking into teaching and learning based on course of study, level of study, age and gender?

\subsection{Hypotheses}

The research questions were translated into the following hypotheses to guide the study.

1) There is no significant difference in undergraduate students' involvement in social networking based on course of study, level of study, age and gender.

2) There is no significant difference in undergraduate students' attitude towards integration of social networking into teaching and learning based on course of study, level of study, age and gender.

\section{Methods}

\subsection{Population of the Study}

The target population consisted of 17,618 undergraduate students in years (levels) 2, 3, and 4 who were enrolled into full time degree programmes in University of Uyo, Akwa Ibom State for 2014/2015 academic session.

\subsection{Sample and Sampling Procedures}

The different faculties were assigned into three cognate groups, these were: Arts/humanities which consisted of faculties of Arts and Law; Social Sciences which consisted of faculties of Environmental Studies, Business Administration, Education and Social Science; and Science which consisted of faculties of Agriculture, Pharmacy, Basic Medical, Clinical, Science and Engineering. Samples were drawn from each of the twelve faculties in the University. Simple random sampling technique was used to select fifty students who were representatives of the target population from levels (year) 2, 3 and 4 respectively; so that 150 students were sampled from each faculty making a total of 1800 students. Copies of the questionnaire were administered to this number and on collation 70 copies of the questionnaire were not properly completed. Thus 1730 respondents actually selected themselves into the sample making $96.1 \%$ return rate.

\subsection{Design of the Study}

The design of study was ex-post facto with a survey approach. This design was considered appropriate for this study since the variables had already occurred and did not require the manipulation of such by the researchers in the course of this study.

\subsubsection{Measure and Covariates}

The instrument used for the study was a researcher developed questionnaire entitled 'Students' Social Networking and Attitude Questionnaire (SSNAQ) which contained 25 items which were drawn on a four-point rating scale of Strongly Agree (SA), Agree (A), Disagree (D) and Strongly Disagree (SD).

Validation of the instrument was carried out by an expert in Curriculum Studies and an expert in Measurement and Evaluation in the University of Uyo. To ascertain the reliability of the instrument, the researchers carried out a trial test using thirty students who were drawn from the population of the study but were not part of the study but who were found to be equivalent in all respects to the sample of the study. The scores obtained from students' responses were subjected to Cronbach's Alpha Statistical Method of Analysis and the result yielded a reliability coefficient of .71.

The researchers administered the instrument on 1800 students with the assistance of respective class representatives and 1730 copies were completed and returned. The instrument were sorted based on variables and scores of 4,3,2 and 1 were assigned to SA, A, D and SD respectively for all positively worded items and 1, 2, 3 and 4 were assigned to SA, A D and SD respectively for all negatively worded items.

\section{Results}

\subsection{Recruitment}

The participants in this study were recruited in October from undergraduate students who enrolled for regular degree programmes in the University of Uyo for 2014/2015. 


\subsection{Statistics and Data Analysis}

Table 1. Analysis of variance (ANOVA) of students' involvement in social networking based on course of study

\begin{tabular}{|c|c|c|c|c|c|}
\hline Course of Study & $\mathrm{N}$ & & $\overline{\mathrm{x}}$ & SD & \\
\hline Arts /Humanities & 275 & 27.16 & & 5.13 & \\
\hline Social sciences & 573 & 29.03 & & 5.84 & \\
\hline Science based & 882 & 26.36 & & 5.92 & \\
\hline Sources of Variation & Sum of Squares & Degree of Freedom & Mean Squares & F-cal & F-crit \\
\hline Between Groups & 2149.82 & 2 & 1074.91 & 41.87 & 2.99 \\
\hline Within Groups & 44327.67 & 1727 & 28.67 & & \\
\hline Total & 46477.49 & 1729 & & & \\
\hline
\end{tabular}

* Significant at $\rho<.05$ alpha level; $\mathrm{N}=1730$.

Table 1 reveals that undergraduate students from Social Sciences had the highest mean score of 29.03 on students' involvement in social networking, followed by Art/Humanities and Science based students with mean response of 27.16 and 26.36 respectively. The inference is that students having the highest mean score get more involved in social networking than others. Table 1 also shows that the calculated F of 41.87 is higher than the F-critical of 2.99 at 0.05 alpha level of significance with 2 and 1727 degrees of freedom. The null hypothesis which stated that there is no significant difference in undergraduate students' involvement in social networking based on course of study is rejected and the alternate hypothesis retained. This means that there is a significant difference in undergraduate students' involvement in social networking based on course of study.

Given the significant F-ratio; a post hoc analysis using Scheffe's Test was done to locate the source of differences. The result of the analysis indicates a non-significant difference exist between Arts/Humanities and Science based as well as Arts/ Humanities and Social Sciences, while a significant difference existed between Social Sciences and Science based students.

Table 2. Analysis of variance (ANOVA) of students' involvement in social networking based on level (Year) of study

\begin{tabular}{|c|c|c|c|c|}
\hline Year of Study & $\mathrm{n}$ & & $\overline{\mathrm{x}}$ & SD \\
\hline 200 level & 594 & & 28.10 & 5.81 \\
\hline 300 level & 588 & & 26.81 & 5.73 \\
\hline 400 level & 548 & & 26.02 & 5.25 \\
\hline Sources of Variation & Sum of Squares & Degree of Freedom & Mean Squares & F-cal F-crit \\
\hline Between Groups & 1175.22 & 2 & 587.61 & $\begin{array}{ll}33.17 & 2.99\end{array}$ \\
\hline Within Groups & 30589.17 & 1727 & 17.17 & \\
\hline Total & 31764.39 & 1729 & & \\
\hline
\end{tabular}

* Significant at $\rho<.05$ alpha level; $\mathrm{N}=1730$.

Table 2 shows that 200 level undergraduate students had the highest mean score of 28.10 , followed by 300 level (26.81) and 400 level (26.02) respectively in their involvement in social networking. This indicates that 200 level undergraduates get more in involved in social networking than 300 level undergraduate students and lastly the 400 level undergraduate students. Table 2 also shows that the calculated F of 33.17 is higher than the critical F of 2.99 at 0.05 alpha level with 2 and 1727 degrees of freedom. Therefore, the null hypothesis which stated that there is no significant difference in undergraduate students' involvement in social network based on year of study is rejected and the alternative hypothesis retained. This implies that there is a significant difference in undergraduate students' involvement in social networks based on year of study. Given the significant F-ratio; a post hoc analysis using Scheffes multiple comparisons was done to locate the source of differences. The result of 
the analysis shows a significant difference between 200 level and 400 level as well as a significant difference between 200 level and 300 level, while a non-significant difference between exists 300 level and 400 level students.

Table 3. Result of independent t-test analysis of students' involvement in social networking based on age

\begin{tabular}{lccccccc}
\hline Age & $\mathrm{N}$ & $\overline{\mathrm{x}}$ & $\mathrm{SD}$ & $\mathrm{df}$ & $\mathrm{t}$-cal & t-crit & Decision at $\rho<.05$ \\
\hline $17-23$ & 1013 & 21.28 & 4.10 & 1728 & 3.00 & 1.96 & $*$ \\
$24-30$ & 717 & 21.85 & 4.14 & & & & $*$ \\
Total & 1730 & 21.72 & 3.98 & & & & \\
\hline
\end{tabular}

* = Significant at $\rho<.05$ alpha level.

Table 3 reveals that the mean score of students within 24 to 30 years (21.85) is slightly higher than the mean score of students with the age range of 17 to 23 (21.28). This shows that students within the age range of 24-30 are more involved in social networking than students within 17-23 years. Table 3 also shows that the calculated $t$ of 3.00 is higher than the critical $t$ of 1.96 with 1728 degrees of freedom at 0.05 alpha level of significance. This indicates a significant difference between the two. Therefore the null hypothesis which stated that there is no significant difference in undergraduate students' involvement in social networking based on age is rejected and the alternative retained. This implies that there is a significant difference in undergraduate students' involvement in social networking based on their age range difference.

Table 4. Result of independent t-test analysis of students' involvement in social networking based on gender

\begin{tabular}{lccccccc}
\hline Gender & $\mathrm{N}$ & $\overline{\mathrm{x}}$ & $\mathrm{SD}$ & $\mathrm{df}$ & $\mathrm{t}$-cal & t-crit & Decision at $\rho<0.05$ \\
\hline Male & 595 & 54.26 & 6.28 & 1728 & 15.67 & 1.96 & $*$ \\
Female & 1135 & 58.49 & 4.93 & & & & $*$ \\
Total & 1728 & 56.22 & 5.84 & & & & \\
\hline
\end{tabular}

* = Significant at $\rho<.05$ alpha level.

Table 4 results shows that the mean score (58.49) of female students involved in social networking was higher than the mean score (54.26) of male students. Table 4 also reveals that the calculated $t$ of 15.67 is greater than the critical $t$ of 1.96 at 0.05 alpha level of significance with 1728 degrees of freedom. The result is significant; therefore, the null hypothesis which stated that there is no significant difference in undergraduate students' involvement in social networking based on gender is rejected and alternate hypothesis retained. This means that there is a significant difference in undergraduate students' involvement in social network based on gender.

Table 5. Analysis of variance (ANOVA) of students' attitude toward integration of social networking into teaching and learning based on course of study

\begin{tabular}{lccccc}
\hline Course of Study & $\mathrm{N}$ & $\overline{\mathrm{x}}$ & \multicolumn{2}{c}{ SD } \\
\hline Arts /Humanities & 275 & & 28.41 & 5.40 \\
Social sciences & 573 & & 26.09 & 5.84 \\
Science based & 882 & & 23.41 & \multicolumn{2}{c}{5.80} \\
\hline Sources of Variation & Sum of Squares & Degree of Freedom & Mean Squares & F-cal & F-crit \\
\hline Between Groups & 4142.34 & 2 & 2071.17 & 83.68 & 2.99 \\
Within Groups & 42751.20 & 1727 & & & \\
Total & 46893.54 & 1729 & & & \\
\hline
\end{tabular}

* = Significant at $\rho<.05$ alpha level; $\mathrm{N}=1730$. 
Table 5 shows that undergraduate students from Arts/Humanities had the highest mean score (28.41), followed by Social Science students (26.09) and lastly Science based students with 23.41 mean score. This implies that Arts/Humanities undergraduate students' attitude towards integration of social network in teaching and learning was more positive and higher than their counterparts in other courses of study. Table 5 also shows that the calculated F of 83.68 is higher than the critical F of 2.99 at 0.05 alpha level with 2 and 1727 degrees of freedom. Therefore, the null hypothesis which stated that there is no significant difference in undergraduate students' attitude towards integration of social networking into teaching and learning based on course of study is rejected and the alternative retained. This implies that there is significant difference in undergraduate students' attitude towards integration of social network into teaching and learning based on their courses of study.

To find the direction of significance, the responses were subjected to Scheffe's multiple comparison of group mean test for post hoc analysis. This indicated a significant difference between Arts/Humanities and Science based, Arts/Humanities and Social Sciences and Social Sciences and Science Based.

Table 6. Analysis of variance (ANOVA) of students' attitude towards integration of social networking into teaching and learning based on level (Year) of study

\begin{tabular}{lccccc}
\hline Year of Study & $\mathrm{n}$ & \multicolumn{1}{c}{} & \multicolumn{1}{c}{ SD } \\
\hline 200 level & 594 & & 27.49 & 6.06 \\
300 level & 588 & & 26.91 & 5.62 \\
400 level & 548 & & 26.50 & 5.74 \\
\hline Sources of Variation & Sum of Squares & Degree of Freedom & Mean Squares & F-cal & F-crit \\
\hline Between Groups & 4205.45 & 2 & 2102.73 & 79.38 & 2.99 \\
Within Groups & 45746.02 & 1727 & 26.49 & & \\
Total & 49951.47 & 1729 & & & \\
\hline
\end{tabular}

$*=$ Significant at $\mathrm{p}<.05$ alpha level; $\mathrm{N}=1730$.

Table 6 reveals that 200 level students mean score (27.49) is highest, followed by 300 level students (26.91) and 400 level students (26.50) respectively. This implies that attitude of 200 level undergraduate students' towards integration of social network into teaching and learning is positively higher than other students at 300 and 400 levels. Table 6 also shows that the calculated F of 29.49 is higher than the critical F of 2.99 at 0.05 alpha level with 2 and 1727 degrees of freedom. Therefore, the null hypothesis which speculated that there is no significant difference in undergraduate students' attitude towards integration of social networking into teaching and learning based on year of study is rejected. This implies that there is a significant difference in undergraduate students' attitude towards integration of social network into teaching and learning based on their year of study.

To find the direction of significance, the responses were subjected to Scheffe's multiple comparison of group mean test for post hoc analysis. This indicated a non-significant difference between 200 level and 300 level, 200 level and 400 level with significant difference in 300 level and 400 level respectively. Though there exist mean differences between the groups; it is only at one point, that is, between 200 and 400 level the significance exists.

Table 7. Independent t-test analysis of students' attitude towards integration of social networking into teaching and learning based on age

\begin{tabular}{lccccccc}
\hline Age & $\mathrm{n}$ & $\overline{\mathrm{x}}$ & $\mathrm{SD}$ & $\mathrm{df}$ & $\mathrm{t}-\mathrm{cal}$ & $\mathrm{t}$-crit & Decision at $\rho<0.05$ \\
\hline $17-23$ & 1013 & 77.22 & 4.86 & 1728 & 2.79 & 1.96 & $*$ \\
$24-30$ & 717 & 76.55 & 5.69 & & & & $*$ \\
Total & 1730 & 76.74 & 4.71 & & & & \\
\hline
\end{tabular}

* = Significant at $\rho<.05$ alpha level.

Table 7 shows that the mean score of students within the age range of 19-23 (77.22) is higher than the mean score of students within the age range of 24-30 (76.55). This implies that the students with the age range of 
17-23 have a higher and positive attitude towards the integration of social networking into teaching and learning than the 24-30 age range of undergraduate students. Table 7 shows that the calculated $t$ of 2.79 is higher than the critical $t$ of 1.96 at 0.05 alpha level of significance with 1728 degrees of freedom. The result is significant; therefore the null hypothesis which stated that there is no significant difference in the attitude of students' towards the integration of social networking into teaching and learning is rejected. This result implies that students' attitude towards the integration of social networking into teaching and learning differ significantly based on their ages with those between the ages of 17 and 23 years being more disposed to the integration of Social Networking into teaching and learning.

Table 8. Independent t-test analysis of student attitude towards integration of social networking into teaching and learning based on gender

\begin{tabular}{lccccccc}
\hline Gender & $\mathrm{n}$ & $\overline{\mathrm{x}}$ & $\mathrm{SD}$ & $\mathrm{df}$ & $\mathrm{t}$-cal & t-crit & Decision at $\rho<0.05$ \\
\hline Male & 595 & 66.81 & 5.77 & 1728 & 40.20 & 1.96 & $*$ \\
Female & 1135 & 60.78 & 4.92 & & & & $*$ \\
Total & 1730 & 63.90 & 4.7 & & & & \\
\hline
\end{tabular}

* Significant at $\rho<.05$ alpha level.

Table 8 shows that the male students have a mean score of 66.81 which is higher than that of their female counterpart with mean score of 60.78 . This revealed that male students' attitude towards the integration of social networking into teaching and learning is higher and positive than the female students. Table 8 also reveals that the calculated $t$ of 40.20 is higher than the critical t of 1.96 at 0.05 alpha level with 1728 degrees of freedom. The result is significant; therefore, the null hypothesis which stated that there is no significant difference in undergraduate students' attitude toward integration of social network into teaching and learning based on gender is rejected. This implies that undergraduate male students' attitude towards the integration of social networking into teaching and learning is significantly higher than that of female.

\section{Discussion}

The result of the analysis showed that there is significant difference in undergraduate students' involvement in social networking with Social Science students having highest involvement in social networking followed by Arts/ Humanities and lastly Science students. This result could be attributed to the nature of their courses. Social Science courses educate and expose students to socialization processes and factors than Arts/ humanities and even the Sciences. Moreso science students more often than not get involved in laboratory and practical work in their studies, thus leaving them with less free time to involve in social networking. This result is at variance with the findings of Ahmad (2011) which showed that there was no significant difference in the extent of social networking sites usage by students based on faculty.

The result of the analysis also showed that there exists a significant difference in the attitude of undergraduate students towards the integration of social networking into teaching and learning based on course of study. Undergraduate students from Arts/ Humanities showed higher and a more positive attitude towards integration of Social networking into teaching and learning, followed by undergraduates from Social Sciences and lastly undergraduate students from the Sciences. This result may be attributed to the nature of courses students undertake. Science based courses generally tend to involve more practical work and empirical studies. Science students may therefore see lesser need for Social networking and ICT in practical. On the other hand Arts-based courses and the humanities rely heavily on collation of theoretical information and facts from different sources. The students in these courses could therefore see higher need for integration of Social networking in the process of teaching and learning. This finding is in consonance with the findings of Ahmad (2012) which showed that there was significant difference in the disposition of university students towards social networking based on faculties. Faculty determines the course of study.

The result of the analysis showed that there was a significant difference in students' involvement in social networking based on year (level) of study. The 200 level undergraduate students had the highest involvement in social networking, followed by 300 level undergraduate students and finally 400 level undergraduate students. This result could be explained by the fact that at the 300 level (penultimate year) and the 400 -level (final year) the students are likely to be more concerned with their academic work because they are more conscious of their Cumulative Grade Point Average and final class of degree on graduation. They are therefore more likely to pay 
greater attention to their academic work than social networking. Furthermore, the final year students may be involving less in social networking because of their final year project (research study) which they undertake. This may take most of their time that they have less time to get involved in social networking. This finding is related to that of Karpinksi and Duberstein (2009) who found that Facebook users averaged 1-5 hours per week while non-users averaged 11-15 per week with regards to hours spent on studying.

The result of the analysis also indicated that there exist a significant difference in the attitude of undergraduate students towards the integration of social networking into teaching and learning based on level (year) of study. The 200 level students were significantly more disposed in their attitude towards integration of social network into teaching and learning than other students at 300 and 400 levels. This may be explained by the fact that 200 level students have more time left to complete their programmes and are more disposed to innovations within the time frame left. The 300 and 400 level students may already be focused on completing their programmes and graduating. They may therefore be less enthusiastic about innovations in the teaching and learning process. The findings of this study is at variance with that of Wolfe (2013) who reported that there was a minimal correlation between gender, class year (level of study) and major course of study.

The result of the analysis revealed that there was a significant difference in undergraduate students' involvement in social networking based on age. Undergraduate students within the age range of 24 to 30 years showed a higher involvement than undergraduate students with age range of 17 to 23 . This may have been due to the undergraduate students' level of maturity (i.e. their chronological age). Those in the age range of 24 to 30 may attach more value or importance to social networking than those between 17 and 23 . The more mature students may also be able to fund internet services than those between 17 to 23 years. The older students are also likely to have wider network of social relationships than their younger counterparts. This finding is at variance with the findings of Ahmad (2011) which showed that there is no significant difference in the extent of social networking site usage by students based on age.

Analysis also revealed that there is a significant difference in the attitude of undergraduate students towards the integration of social network into teaching and learning based on their age. Conversely undergraduate students within the age range of 17- 23 have a higher and positive attitude towards the integration of social networking into teaching and learning than 24-30 age range of undergraduate students. This could be due to the fact that undergraduate students within age range 17-23 are much younger and are eager to explore and study new things. They are also likely to be in lower levels of study and still have much time left to graduate than those within the age range of 24-30 who are more likely to be at the penultimate or final year on their programmes. This finding is at variance with the findings of Ahmad (2012) which showed that there is no significant difference in the disposition of university students towards social networking based on age. However, it is to be noted that the investigation by Ahmad (2012) was on attitude of Nigerian University students towards Social network sites generally. This present study focused on University students' attitudes towards integration of Social networking into the teaching/learning prorgammes.

The result of analysis showed that there exists a significant difference in male and female undergraduate students' involvement in social networking, with female students having higher involvement. This may be due to the fact that females like to spend time chatting, posting and meeting new friends than males. The result of the analysis also shows that there is a significant difference in the attitude of undergraduate students towards the integration of social networking into teaching and learning based on gender. Conversely male undergraduate students showed a higher and positive attitude towards integration of social networking into teaching and learning than female undergraduate students. This result could be explained by the fact that male students are more technology driven than females. This finding is at variance with the findings of Ahmad $(2011,2012)$ which showed that there is no significant difference in the disposition of university students towards social networking based on gender.

\section{Conclusion}

From the findings of the study it is concluded that most undergraduate students in the University of Uyo get involved in social networking and the level of this involvement increases as the level of studies and age-range get higher. Conversely the attitude of undergraduate students toward integrating social networking into teaching and learning process declines as the level of studies and age range increases. Also female undergraduate are more involved in social networking than their male counterparts but the males are more positively disposed to the integration of social networking into the teaching and learning process. 


\section{Recommendations}

Based on the findings of the study and conclusion drawn, the following recommendations are made:

1) The university should introduce and implement institutional policies on the use of social media in the university environment.

2) The university management should fund the purchase of ICT gadgets and the training of university staff on ICT.

3) The university should support lecturers and students in terms of adopting new technologies and innovations.

4) The university should approve and organize capacity building and training for lecturers on ICT and integration of social networking sites into teaching and learning.

5) The university should also plan its curricula to reflect integration of social networking sites and this should begin, whenever it is implemented, at the first year and progressively carried through the entire programme.

\section{References}

Ahmad, S. A. (2011). Social networking sites usage and students' attitudes towards social behaviours and academics adjustment in Northern Universities. E Theses UUM ETD/Universiti Utara Malaaysian Electronic Theses and Dissertation. Retrieved from http://etd.uum.edu.my/2801/

Ahmad, S. A. (2012). Attitudinal disposition of Nigerian university students towards social networking sites. International Journal of Emerging Technologies in Learning, 7(1) 71-80. http://dx.doi.org/10.3991/ijet.v7i1.1677

Ajzen. (1980). Theory of reasoned action. Retrieved from http://www.en.wikipedia.org/wiki/Theory_of_reasoned_action

Anwar. (2003). Attitude. Psychology of Personality Education in Online, 4(1) 22-26. Retrieved from http://www.rwkyna.blogspot.com/2011/11/attitude psychnology of personality.html

Boyd, D. M., \& Ellison, N. B. (2007). Social network sites: Definition, history, and scholarship. Journal of computer-mediated communication, 13(1), 210-230. http://dx.doi.org/10.1111/j.1083-6101.2007.00393.x

Jeff, G. (2015). Attitude (Psychology). $\quad$ Retrieved from http://www.en.m.wikipedia.org/wiki/Attitude_(Psychology)

Johnson, L. F., Levine, A., \& Smith, R. S. (2007). Horizon Report (electronic Version). Retrieved from http://www.nmc.org/pdf/2007

Karpinski, A., \& Duberstein, A. (2009). A description of facebook use and academic performance among undergraduate and graduate students. Paper presented at the 2009 American Educational Research Association Annual Meeting, San Diego, CA.

National School Boards Association. (2007). Rising above the gathering Storm: Energizing and Employing America for a Brighter Economic feature. Washington DC: The National Academic Press.

Ophus, J. D., \& Abbitt, J. T. (2009). Exploring the potential perceptions of social networking systems in University courses. Merlot Journal of online learning and teaching, 5(4), 639-648.

Oye, N., Helou, M. A., \& Ab. Rahim, Z. Z. (2012). Students' perception on social networking sites influence on academic performance. International Journal of Social Networking and Virtual Communities, 1(1), 540-550. http://dx.doi.org/10.11591/socnetvircom.v1i1.540

Wolfe, A. M. (2013). Students attitudes towards social networks and learning modalities. 


\section{Appendix}

Table 1(b). Scheffe's post hoc test from multiple comparison of group mean of students' involvement in social network based on course of study

\begin{tabular}{lcc}
\hline Course of Study & Mean Difference & Decision \\
\hline Arts/Humanities versus science based & 0.80 & Not significant \\
Arts/Humanities versus social sciences & -1.87 & Not significant \\
Social sciences versus science based & 2.67 & Significant \\
\hline
\end{tabular}

Critical value different 1.00 .

Table 2(b). Scheffe's post hoc test from multiple compassion of group mean of students' involvement in social network based on year of study

\begin{tabular}{lcc}
\hline Year of Study & Mean Difference & Decision \\
\hline 200 level and 300 level & 1.29 & Significant \\
200 level and 400 level & 2.08 & Significant \\
300 level and 400 level & 0.79 & Not significant \\
\hline
\end{tabular}

Critical value different 1.83 .

Table 5(b). Scheffe's post hoc test from multiple compassion of group mean of students' attitude towards integration of social networking into teaching and learning based on course of study

\begin{tabular}{lcc}
\hline Year of Study & Mean Difference & Decision \\
\hline Arts/Humanities versus science based & 5 & Significant \\
Arts/Humanities versus social sciences & 2.32 & Significant \\
Social sciences versus science based & 2.68 & Significant \\
\hline
\end{tabular}

Critical value different 1.39 .

Table 6(b). Scheffe's post hoc test from multiple comparison of group mean of students' attitude towards integration of social networking into teaching and learning based on year of study

\begin{tabular}{lcc}
\hline Year of Study & Mean Difference & Decision \\
\hline 200 level and 300 level & 0.58 & Not Significant \\
300 level and 400 level & 0.41 & Not Significant \\
200 level and 400 level & 0.99 & Significant \\
\hline
\end{tabular}

Critical value different 1.27 .

\section{Copyrights}

Copyright for this article is retained by the author(s), with first publication rights granted to the journal.

This is an open-access article distributed under the terms and conditions of the Creative Commons Attribution license (http://creativecommons.org/licenses/by/4.0/). 